\title{
Correction to: Intra-bone nuclear DNA variability and STR typing success in Second World War first ribs
}

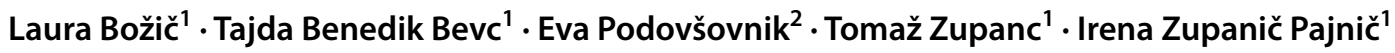

Published online: 4 September 2021

c) Springer-Verlag GmbH Germany, part of Springer Nature 2021

\section{Correction to: International Journal of Legal Medicine (2021)} https://doi.org/10.1007/s00414-021-02681-1

The data for the last column in the Table 1 were missing during the online publication of the original article. The corrected Table 1 is presented here.

Table 1 Descriptive statistics for the Auto target and Auto/Deg ratio or degradation index (for each rib bone part separately)

\begin{tabular}{|c|c|c|c|c|c|c|c|}
\hline & & $\begin{array}{l}\text { Auto target } \\
{[\mathrm{ng} / \mu \mathrm{l}] \text { (proxi- }} \\
\text { mal) }\end{array}$ & $\begin{array}{l}\text { Auto/Deg ratio or } \\
\text { degradation index } \\
\text { (proximal) }\end{array}$ & $\begin{array}{l}\text { Auto target } \\
{[\mathrm{ng} / \mu \mathrm{l}] \text { (mid- }} \\
\text { dle) }\end{array}$ & $\begin{array}{l}\text { Auto/Deg ratio or } \\
\text { degradation index } \\
\text { (middle) }\end{array}$ & $\begin{array}{l}\text { Auto target } \\
{[\mathrm{ng} / \mu \mathrm{l}]} \\
\text { (distal) }\end{array}$ & $\begin{array}{l}\text { Auto/Deg ratio or } \\
\text { degradation index } \\
\text { (distal) }\end{array}$ \\
\hline \multirow[t]{2}{*}{$\mathrm{N}$} & Valid & 29 & 29 & 29 & 29 & 29 & 29 \\
\hline & Missing & 0 & 0 & 0 & 0 & 0 & 0 \\
\hline Mean & & 0.207569 & 16.530000 & 0.043759 & 18.266897 & 0.112069 & 13.918966 \\
\hline Std. Error of Mean & & 0.0350359 & 3.2190394 & 0.0081463 & 5.9481165 & 0.0181448 & 2.6355056 \\
\hline Std. Deviation & & 0.1886742 & 17.3350576 & 0.0438690 & 32.0315875 & 0.0977128 & 14.1926322 \\
\hline Skewness & & 1.088 & 1.909 & 1.661 & 4.196 & 1.239 & 2.095 \\
\hline Std. Error of Skewness & & 0.434 & 0.434 & 0.434 & 0.434 & 0.434 & 0.434 \\
\hline Kurtosis & & 0.477 & 3.180 & 3.635 & 19.655 & 2.154 & 4.107 \\
\hline Std. Error of Kurtosis & & 0.845 & 0.845 & 0.845 & 0.845 & 0.845 & 0.845 \\
\hline Minimum & & 0.0022 & 2.4600 & 0.0017 & 2.2800 & 0.0010 & 1.9800 \\
\hline Maximum & & 0.6748 & 71.1800 & 0.1950 & 171.0300 & 0.4192 & 58.1700 \\
\hline
\end{tabular}

The original article has been corrected.

Publisher's note Springer Nature remains neutral with regard to jurisdictional claims in published maps and institutional affiliations.

The original article can be found online at https://doi.org/10.1007/ s00414-021-02681-1.

Irena Zupanič Pajnič

irena.zupanic@mf.uni-lj.si

1 Institute of Forensic Medicine, Faculty of Medicine,

University of Ljubljana, Korytkova 2, 1000 Ljubljana,

Slovenia

2 Faculty of Tourism Studies - Turistica, University

of Primorska, Portorož, Slovenia 